\title{
The Expression of Feeling in Imagination
}

\section{Citation}

Moran, Richard. 1994. The expression of feeling in imagination. The Philosophical Review 103(1): 75-106

\section{Published Version}

http://dx.doi.org/10.2307/2185873

\section{Permanent link}

http://nrs.harvard.edu/urn-3:HUL.InstRepos:3153296

\section{Terms of Use}

This article was downloaded from Harvard University's DASH repository, and is made available under the terms and conditions applicable to Other Posted Material, as set forth at http:// nrs.harvard.edu/urn-3:HUL.InstRepos:dash.current.terms-of-use\#LAA

\section{Share Your Story}

The Harvard community has made this article openly available.

Please share how this access benefits you. Submit a story.

Accessibility 


\section{DUKE}

\section{Philosophical Review}

The Expression of Feeling in Imagination

Author(s): Richard Moran

Source: The Philosophical Review, Vol. 103, No. 1 (Jan., 1994), pp. 75-106

Published by: Duke University Press on behalf of Philosophical Review

Stable URL: http://www.jstor.org/stable/2185873

Accessed: 26/06/2009 16:05

Your use of the JSTOR archive indicates your acceptance of JSTOR's Terms and Conditions of Use, available at http://www.jstor.org/page/info/about/policies/terms.jsp. JSTOR's Terms and Conditions of Use provides, in part, that unless you have obtained prior permission, you may not download an entire issue of a journal or multiple copies of articles, and you may use content in the JSTOR archive only for your personal, non-commercial use.

Please contact the publisher regarding any further use of this work. Publisher contact information may be obtained at http://www.jstor.org/action/showPublisher?publisherCode=duke.

Each copy of any part of a JSTOR transmission must contain the same copyright notice that appears on the screen or printed page of such transmission.

JSTOR is a not-for-profit organization founded in 1995 to build trusted digital archives for scholarship. We work with the scholarly community to preserve their work and the materials they rely upon, and to build a common research platform that promotes the discovery and use of these resources. For more information about JSTOR, please contact support@ jstor.org.

Duke University Press and Philosophical Review are collaborating with JSTOR to digitize, preserve and extend access to The Philosophical Review. 


\title{
The Expression of Feeling in Imagination
}

\author{
Richard Moran
}

What has come to be known as the problem of "fictional emotions," that is, emotional responses directed upon what are known to be fictional characters and events, presents a useful case for considering the relations between philosophical theorizing about the arts and the critical and artistic thinking that is more internal to the practice and reception of the arts themselves. As an intellectual problem, it provides one good place for investigating what sort of need it is that current philosophical aesthetics is meant to answer to, and how it answers to that need. For it is, of course, not only philosophers who have been theoretically concerned with the place of feeling in aesthetic response. The question of the legitimate role (if any) of emotion in the reception of, for example, literature and theater, is itself a sharply contested matter with its own history, and it's not hard to see the conflicts over this role as defining many of the most consequential developments in the arts over the past century. In this connection, we may recall such developments as the nineteenth-century reaction against Romanticism, and later against Victorian sentimentalism; Modernism and the suspicion of dramatic emotion as a form of bad faith; the theorization of the role of feeling in the theater of Brecht or of Artaud; or the rejection of all forms of mere empathy in favor of the identification of the power of art with the ability to scandalize or unsettle. Whether or not philosophical aesthetics can or should contribute to such debates themselves, it does seem an imperative upon any good philosophical analysis of the role of emotion in the mimetic arts that such critical and artistic struggle should remain comprehensible within such an account. It ought to put us in a better position to understand what is at stake, for example, in the difference between being moved and being manipulated, or between emotional responsiveness and voyeurism.

The problem of emotions and fictions that occupies the attention of contemporary philosophers, however, poses the prior question of how it is so much as possible for a person to get emotionally worked up over what she knows to be unreal, merely fictional. One of my claims will be that aspects of the philosophical construal of 
the phenomenon of fictional emotions give a misleading picture of our relations to fictions in general, and make it more rather than less difficult to pose the sorts of critical questions about art and emotional engagement just mentioned. On a better understanding of imagination and feeling, the metaphysical problem of fiction and emotion should not arise. Part of the remedy, I will suggest, lies in loosening the grip of a concept of imagination that is exclusively concerned with the representation of various states of affairs, that restricts interest in it to the imagining of various fictional truths, and thus suggests an unreal discontinuity between what and how we imagine and our real life engagements in everyday life. The relation between such engagements and our acts of imagining in fictional contexts is examined in the final section of the paper, which discusses a problem from Hume concerning the phenomenon of moral and emotional resistance in imagination.

1.

In many ways the best and most comprehensive contemporary discussion of the problem of fictional emotion is found in Kendall Walton's recent book Mimesis As Make-Believe, ${ }^{1}$ and I will begin by using it as representative of the current formulation of the problem and the space of possible solutions. The general form of the problem, however, and the general picture of aesthetic response that gives rise to it, are widely represented in philosophical discussion. The core of Walton's theory of representation in general, and the emotional response to representations in particular, is the development of a concept of make-believe. And this concept, in turn, is explicated in terms of games played with props of various kinds (for example, a hobby horse, a painting) in which various propositions are imagined as true, which is to say that it is a prescription of the game that various propositions are to be treated as true-inthe-fiction, or "fictionally true" (where this need not exclude their happening to be actually true as well). These will include such things as, say, that the doll in one's lap is a baby, that one is witnessing the slaying of Macbeth, or that one is looking at Washington Crossing the Delaware. And such fictional truths will also in-

\footnotetext{
${ }^{1}$ Cambridge: Harvard University Press, 1990. Page references in the text are to this book.
} 
clude, crucially, such propositions as that one is now experiencing fear and pity for the tragic hero, or that one feels the satisfactions of vengeance when rough justice is meted out to the deserving. All of this is not to deny that the audience may be really feeling something, indeed something very intense. It's just not the same thing as real fear or pity (247). And Walton doesn't claim that one cannot also feel genuine fear in the theater, only that one need not feel it when one is in the familiar situation we call being "caught up in the experience." ${ }^{2}$

A decisive moment in the development of any philosophical theory is the step when some paradox is generated out of something that looked familiar and innocuous. So in this case, we might ask, where exactly is the paradox in experiencing lust or fear or sadness elicited by what one knows to be a fictional representation? The rough idea seems to be that, say, to be afraid you must think you're in some kind of danger, and yet you know that the apparent object of your apparent fear is not real, so you know you are not in danger, and yet you seem to be stricken with fear. And to put Walton's account in drastically abbreviated terms: the answer to this problem is that one is experiencing what he calls quasi-fear, pretending really to be afraid, as part of a game of make-believe in which the movie or story is a prop. Among the fictional truths being imagined here are propositions concerning what one is feeling, as well as those concerning fictional characters and events.

However, to get some perspective on our original situation of fear-at-the-movies (or the theater, etc.), we should consider the more general phenomenon of emotionally charged relations to what is known to be in some sense nonactual. For the generation of a paradox of fictional emotions requires a contrast with some central set of unproblematic cases of emotional responses, cases that do not raise such questions, and that presumably involve responses to real persons and events to which we are actually present. And yet at the same time, it is not clear to what extent the paradigms of our emotional involvements, which the fictional cases

\footnotetext{
${ }^{2}$ Two final points: Walton seems to agree that the feelings we experience in response to artworks are not purely voluntarily produced, as the analogy with games of make-believe might suggest (242). And last, if he claims that we don't really care about Emma Bovary or Roderick Spode, he insists that we do care a great deal about the experience of fictionally caring about such things, and are not irrational to do so (271).
} 
should be deviations from, do in fact fit such a pattern. To begin with, think of our concern, emotional and otherwise, directed at various modal facts; things that might have happened to us but didn't, things we might have done, how things could have turned out differently. Such attitudes are central instances of ordinary emotional responses, and it is central to them that they are directed upon "what might have been." Or, for a different type of case, think of spontaneous empathetic reactions such as wincing and jerking your hand back when someone else nearby slices into his hand, even though you know that you are in no danger then of cutting yours. The case could be made to look paradoxical ("wincing in someone else's pain"), but removing this sort of thing from our paradigm set of ordinary emotional responses would leave us with an artificially restricted idea of a norm for emotions. Similarly, the person who says that it still makes her shudder just to think about her driving accident, or her first date, is exhibiting one of the paradigms of emotional response, not an exception to the norm. Now admittedly these will be responses to some real event, even if in the past. Nonetheless, I think the comparison with the case of fiction is still appropriate here since if shuddering in a movie theater is paradoxical, then so ought to be shuddering sitting safely at home years after one's experience. And even if one were inclined to consider them both irrational somehow, one would thereby lose what was supposed to be distinctive about the fictional case.

Rather, it begins to look like comparatively little of one's emotional attention concerns objects in the actual here and now. Indeed, it does often appear as though most of the suffering and satisfaction in life takes place either prior to the expected events that are supposed to deliver the real goods; or after the fact, savored in remembrance or sticking in one's craw, as the case may be. And the intuitions of our everyday psychology appear deeply ambivalent concerning such temporal perspectives. Relief, regret, remorse, and nostalgia are, after all, among the paradigm cases of emotional response; and although they are essentially backwardlooking, they are not commonly thought to present any special puzzle among the emotions. But at the same time, from within everyday psychology we have also to confront the proverbial injunction against crying over spilt milk, which can itself seem very puzzling. 
After all, if we can't cry after the milk is spilled, when can we cry? Presumably not upon confronting the milk still safely in the bottle.

A related ambivalence obtains in our intuitions with respect to longer-term relations to the past. Yet even though something about the nonactuality of what one is focusing on is indeed pointed to in such expressions, these emotions and their objects don't look like they demand explanation as deviations from the normal conceptual requirements of emotions. Responses like these are the norm, in terms of which anything different would have to be explained. Naturally, it is not the case that just any possibility, however remote, provides an appropriate object for emotional response. There is surely something wrong with the reaction of Grimm's Clever Else to the contemplation of a far-off possible misfortune. And different emotion types will vary a great deal in their fittingness with differences in temporal perspective and distance from the actual. My claim at this point is not that actuality or fictionality never make a difference to the appropriateness of some emotional reaction, but rather that our paradigms of ordinary emotions exhibit a great deal of variety in this respect, and that the case of fictional emotions gains a misleading appearance of paradox from an inadequate survey of examples. (In a restricted way, the following section discusses some of the differences in specifically artistic fictions that contribute to making the connection between the bare possibility of some event and the actual engagement with one's emotional life.)

In connection with the idea that, say, the emotion of fear requires belief in the present actuality of danger to oneself, it is worth noting that the horror movie example of Walton's that is the test case throughout his discussion, as well as many others, is in important respects a nonstandard case of the inducement of feeling at the movies. And the atypical feature of this case produces a much sharper sense of paradox than would be provided by other more ordinary cases. For the situation involves a horror movie in which the monster fixes its gaze on the camera and then proceeds in the direction of attacking the viewers, and not toward any character in the film (196). The sense of paradox here gains from the implied contrast with the analogous situation outside the movie theater: if you were really under such a threat, then recoiling in horror would make sense, but here you are aware that this is only fictional, and therefore your response may appear puzzling. 
However, suppose the example were of the more usual case of fear and horror experienced at a movie in which it is the characters on the screen who are subject to gruesome attacks of various kinds. Here the real-life counterpart situation would be that of really seeing someone else attacked, and then recoiling in fear and horror. This sort of real-life reaction is not itself any more paradoxical than the first real-life case of recoiling from a threat to oneself. But notice that this type of case involves features that are adduced as contributing to the paradoxical character of the original case of fictional emotion involving the movie monster advancing toward the camera. For in seeing someone else attacked, I may be well aware that $I$ am in no danger myself. I am not at that moment confusing myself with the other person, and yet $\mathrm{I}$ am wincing as if in pain, recoiling as from a threat, filled with fear and horror. But this is the real-life situation, which is not supposed to raise the same questions as the fictional situation does. It is in failing to conform to this real-life paradigm that the fictional cases are to be considered paradoxical. The fictional analogue to this ordinary case of empathy is the more usual case of experiencing horror directed at what is happening to the victims on the screen (that is, rather than fear for one's own safety and bodily integrity). Hence this would serve much less well as an example to stimulate the sense of paradox, for it would raise the question of just how different the fictional situation is from the real-life situation. It might be objected at this point that we at least have to believe that the attack is real in order to experience horror, but I think this needn't be so. One's reaction may be similar, for example, to the extreme discomfort most people feel who are witnessing surgery for the first time, even if they are aware that no one is currently feeling any pain. One might still wonder whether it is precisely fear that is felt in witnessing another's pain, but whatever we want to call it, the affect and the recoiling in horror don't seem essentially different from what goes on in the movie theater, which is the original phenomenon to be accounted for. ${ }^{3}$

\footnotetext{
${ }^{3}$ For further discussion of some of these issues, including responses from Walton, see the symposium discussion of Mimesis as Make-Believe in Philosophy and Phenomenological Research 51 (1991): 379-431. See also Noel Carroll's discussion of Walton in The Philosophy of Horror (London: Routledge and Kegan Paul, 1990).
} 
It is unlikely that the various responses we classify with the emotions form anything like a natural kind: some are more tied to judgments than are others, some require more in the way of definite objects than do others, some are more socially structured than others, some are more deliberately cultivated than others, some are more simply and passively contagious than are others. For this reason it is unlikely that there could even in principle be a general problem of fictional emotions. Even the paradigm theatrical responses of laughter and tears do not parallel each other here. For whatever air of paradox there might be in the idea of pity or fear directed at what are mere characters, there is none at all in the idea of, say, mirth and merriment directed at events one knows to be staged, or at tales concerning salesmen or chickens who never really lived. Nor, I think, are various other aesthetically relevant feelings such as pleasure, boredom, disgust, anxiety, or suspense conceptually dependent on any beliefs about the real existence of their objects. (And how different from varieties of disgust is the horror experienced at many horror movies, the central and favored example for generating the paradox of fictional emotions?) And it is not only the variety of what we call emotions, but also the lack of sharp boundaries between them, that casts doubt on the idea of a general philosophical problem of emotions and fictions. There is a continuum of cases from the types of emotions that fall outside the problem altogether (for example, surprise), and the diverse cases of fear, or pity, or vengeful satisfaction, which would seem our best candidates for paradox. Many of the most aesthetically relevant emotional responses will lie somewhere between these poles.

The sentiments that are tapped by works of art are various not only in the thoughts and feelings associated with them, but in their sources in the person, in their kinds of directedness, and in their relation to the thing that most immediately elicits them. Their directedness need not always require a full-fledged intentional object. If people can respond with emotion to some nonfigurative work of painting or music, which provides no scenario for them to make-believe is true, then perhaps what makes the difference between works that are emotionally engaging and those that aren't is not a matter of aptness for make-believe or the generation of 
additional fictional truths, but rather a difference in certain other features. In the theater, for instance, we might think of the various nonmimetic effects of such things as music (including song), lighting, figurative language, pacing, and compression of time, and other effects that provide emotional punctuation and tone, but do not necessarily represent anything themselves, and indeed may be quite mimetically out of place in the scene presented. They may thus directly impair the aptness for make-believe, without contributing any additional fictional truths of their own, while yet being directly responsible for the emotional involvement of the audience.

The philosophical paradox of fictional emotions, however, is constructed by the separation of these sources and aspects of aesthetic emotion from those relating more directly to mimetic features. In framing the philosophical problem, the implied contrast is always with the real thing, because the very thing to be explained is how (awareness of) fictionality is compatible with the appearance of genuine emotional attitudes. This naturally encourages the idea that it is the sense of fictionality that needs to be overcome, or diminished, or distracted from, if we are to make sense of such responses. And this, in turn, encourages the idea that artificiality, the assertion of the status of the work as artifact, or the elaboration of conspicuous features that play no role in the construction of any fictional truths, must detract from emotional engagement in thus detracting from the coherence of the fictional world depicted. It is, I believe, the framing of the original problem itself that leads the mind in this direction, and not just among philosophers but also on the part of some of those seeking to keep their audiences stimulated. So it makes sense along these lines that among the features that Walton sees as typically inhibiting psychological participation are such things as the "conspicuous brush strokes on the surface of Van Gogh's Starry Night' (277), and in general what he calls the ornamental features of artworks that highlight the artificial character of the prop. ${ }^{4}$ As he says in the section called "Appreciation Without Participation," "'gratuitously flowery or alliterative or otherwise self-conscious language may take on a life of its

\footnotetext{
${ }^{4}$ In this his ideas are not so different from those of various Modernist writers, such as Bertolt Brecht, concerning what makes for alienation and the preservation of emotional distance in the theater. See, for example, "A Short Organum for the Theater," in Brecht on Theater, ed. and trans. John Willet (New York: Hill and Wang, 1964).
} 
own, calling attention to itself at the expense of the thing described'” (276).

Walton's point is not to take sides in any dispute between aesthetic Formalists, Realists, or others, but rather to say something about the sources of emotional engagement with mimetic works. Nonetheless it does seem that if we arrive at this conclusion about the various formal and figurative elements of a work, we must have been going after the problem of emotional participation the wrong way around. For it would appear to be the very features of the work that do indeed detract from the realistic presentation of the fictional world that actually enhance, and don't inhibit, the intensity and richness of one's emotional involvement with it. We know that Starry Night would not really be more emotionally engaging if Van Gogh had calmed down and left out all that overwrought brush work. And the highly artificial, figurative, self-conscious language spoken, for example, by Macbeth does not interfere with our ability to be gripped by the play and his situation. So we seem to have gone wrong somewhere. The very expressive qualities that disrupt any sense of a fictional world are in fact central for our psychological participation with artworks. But if such emotional engagement is to be explained in terms of the imagining of various fictional truths, about the fictional world and about one's relation to it, it seems that this is just what should not be so.

It will be helpful in thinking about this to compare different ways of presenting fictional truths. There are, after all, many different kinds of fictional representation, and it is only some representations of, say, even quite frightening things that induce even quasi-fear. When we consider the variety of representations there are (stick figures, case histories, billboards, ...), it is clear that most do not induce any such thing. For instance, few tears are shed over the Cliff Notes of even the most lurid tales, and some genres of writing-medical or military, for instance-find it important to drain the language of anything that may induce affective response. And yet these will often describe some pretty nasty situations. Merely to add greater length or descriptive fidelity needn't make any difference to their effectiveness either. So what is it that needs to be altered or added to such a representation for it to be capable of inducing anything like fear? The answer encouraged by both problem and solution as presented lies, I think, in the direction of cultivating the sense of realism on the part of the audience, the 
sense that what they are witnessing is really there and they are present to it. This sort of answer is also encouraged by the prominent role of the example of movies, especially horror movies, in many recent discussions of responses to fictions.

But if we get away from this example for a while and consider written works, things may look different. Going from a straight, "flat," uninspiring description of some event to an emotionally charged one is typically not a matter of making the account more and more faithful to real life. Nor are the transformations of style and detail relevant to emotional responsiveness typically those that move in the direction of making the work itself-the writing itself-withdraw from sight by deflecting attention from formal or material features of the medium. Instead what are typically involved are all the resources of figuration, allusion, rhythm, repetition, assonance, and dissonance; all elements that make what we are reading or hearing less like something that we could makebelieve is real, or a true record of anything. And after all, it is the use of rhetorical tropes and techniques like these that is responsible for the ancient charge against rhetoric itself that it is mere appealing to the emotions; but the way such rhetorical features work on the emotions does not seem to rely on either believing or making-believe something to be the case.

Such expressive qualities of a work, and their central role in engaging the emotional life of reader or audience, don't seem to find a natural place within the theory of make-believe, or the original problem to which it is a solution. Not only don't they usually contribute to making something fictionally true, but they introduce elements that are often impossible to imagine as part of any fictional world. And yet their contribution to what the audience feels is direct and profound. If eliminating them made a work more apt as a generator of fictional truths, the work would also by that very fact lose most of its emotional power. The language put into the mouth of someone like Macbeth is fairly remote from anything one could imagine anyone really speaking, and it would be an unrewarding exercise to imagine a different world in which ordinary people actually expressed themselves that way. But in the right hands, it is the very features responsible for this resistance to makebelieve that are responsible for one's emotional involvement in the scene, as in his haunted soliloquy on sleep. 
- the innocent sleep,

Sleep that knits up the ravelled sleave of care, The death of each day's life, sore labor's bath, Balm of hurt minds, great nature's second course, Chief nourisher in life's feast.

What engages the audience's emotion in such language is not either imagining that someone could really be talking this way, or making-believe that sleep is something that both knits and is eaten and is bathed in. Such category crossing would be avoided if, instead of this speech, Macbeth had simply said, "I could really use a rest." And then in some sense the distance between our world and the fictional world of the play would be less, but our distance from Macbeth and his state of mind, or the consciousness of the play itself, would be much greater.

The difference in self-consciousness and artifice between unobtrusive language and the language actually used in the play is not a difference that must be compensated for in other ways if the speech is to engage the emotions of the audience. Rather, it is just such artifice in rhythm and figuration that is directly responsible for the ability of these lines to elicit any feeling. And this is largely because these features do not just make the language picturesque, but are expressive of a certain complex attitude toward sleep, and exile from it, at this moment in the play. The outlandish character of some of the comparisons, the rhythm of the relentless piling up of image upon image, like an obsessive thought, the very unreality of it-these things are directly productive of feeling on the part of the audience, and not through their role, if any, in make-believe. It is undeniable that the emotions are engaged by something we call imagination here, but it would be forcing things to construe the imagination relevant here as making-believe that some set of propositions is fictionally true. The point is not that figuration and other expressive qualities constitute a counterexample to a particular theory of fictional emotions, but that the role of fictionality in the original presentation of the paradox points in the wrong direction for understanding the role of emotion in aesthetic response. For it is such expressive qualities of a work that typically make the difference between representations that are arousing and those that aren't, and these very qualities, like expressive brush 
strokes or highly chromatic colors, not only disrupt the closure of the fictional world, but typically contribute nothing of their own to the generation of fictional truths about the world depicted. The fictional nature of what is responded to needn't raise any special question about the coherence of one's emotional response, and the constructing and imagining of fictional truths does not account for the difference made by those representations that actually do engage the emotions. There is nothing in the artificial character of expressive qualities that needs to be compensated for on the side of the imagining of fictional truths.

\section{3.}

The role of imagination is obviously crucial in all of these examples, and to that extent I am not in disagreement with Walton or other theorists of fictional emotions. At issue, however, is whether "imagination" has a uniform and explanatory meaning in the various cases. The sense of "imagination" I have been drawing attention to in the examples of the effects of figurative language has less to do with simply imagining something to be the case, or imagining doing or feeling something, and more to do with what we ordinarily think of as "imaginativeness." This concerns the ability to make connections between various things, to notice and respond to the network of associations that make up the mood or emotional tone of a work. So it will include, for instance, the ability and inclination to attend to the associations of innocence and death in Macbeth's speech; or the recurrence of imagery of the routines of eating, bathing, sleeping, mending-the rhythm of the domestic household of which he is host, and whose peace and security he has just outraged; or even the ability to appreciate the contrast and disanalogy in some figurative comparison (the "ravelled sleave of care" indeed). Someone who lacks imagination in this sense is not handicapped by the inability to imagine some state of affairs. It would not be like the inability to hear a tune in one's head, or the inability to rotate the mental image of a cube for an experimental psychologist. Imagination comes in many varieties, as do its relation to rationality as well and its relation to what we feel. Perfectly normal people may vary a great deal in their abilities to exercise the kind of imaginativeness just described, and possession of the ability itself is very much a matter of degree. By contrast, if a person can 
engage in counterfactual reasoning at all, he should be able to imagine the truth of any proposition he understands, in the sense of making a simple hypothetical supposition. It would call for a rather special explanation if, in response to the instruction to imagine, say, that you have five apples and lose two of them, you were to reply, "I can't seem to imagine that; could you make it five oranges instead?" An inability to imagine of this kind, that applied to just some of the propositions one understands, would raise questions of a very different kind from the partial or selective ability to make connections in a network of metaphorical associations, or, say, to put oneself in the place of someone one has wronged.

What sort of imagination is relevant to one's emotional engagement with fictions, and what is it directed upon? On Walton's account, it is essential that part of what is imagined has a content referring to oneself (28-35). So in addition to imagining Macbeth's fear and apprehension and sleeplessness, I imagine that I myself am in some congruent emotional state. But on any philosophical account of such responses, the relevant imagining is held to require something more than the simple counterfactual supposition of some proposition or set of propositions. We don't expect much pity or terror from just a synopsis of the fictional truths prescribed by the plot of Macbeth. So at this point, philosophers will often appeal to something called "vividness" to account for the difference between simply accepting something as fictionally true (or "to be imagined") and the imagination involved in getting caught up in the story. It remains to be seen, however, whether this notion can be understood in a way that is independent of the phenomenon of fictional emotion itself, so that it can be (partially) explanatory of it. When someone speaks of an especially vivid memory, and this doesn't simply mean that it is a memory that is still charged with emotion for her, it is usually a visual memory of some sort that the person has in mind. ${ }^{5}$ But an especially clear or vivid memory, even when it is a visual memory, does not mean a memory-image that is especially clear and sharp in outline or bright in color. As far as brightness and clarity of the image goes, you might be in no better position than someone who has no memory of the

\footnotetext{
${ }^{5}$ In the case of nonvisual memories it's even less clear that vividness could mean anything other than the sense of emotional engagement we are trying to explicate.
} 
event when it comes to knowing what event it is, who the people represented in the image are, or even that it is a memory-image rather than an invention. And yet nothing could count as a vivid memory that didn't include intentional awareness of these other sorts. ${ }^{6}$ And similar considerations apply to the difference between vivid and nonvivid imaginings. Even in those cases where the imagining does involve a mental image of some sort, vividness is not given by any phenomenological features of that image.

Rather than looking to the phenomenological content, Walton's account looks instead to a difference in propositional content to explain fictional emotion, the difference made by imagining, for example, the fictional truth "I am now experiencing fear" (242). It seems that this idea is meant to replace the (empty) appeal to vividness in other accounts to describe the difference between imagining with or without emotional engagement. Otherwise, if there will still be a difference between the vivid and the nonvivid on the level of the first-person imagining that, for example, I am grieving, it would seem that we will not have gained anything in appealing to first-person imaginings in the first place. In fact, I believe, an appeal to self-referring content of imagining can do no better than an appeal to the qualitative features of the image to account for the difference between representations that are and those that are not emotionally engaging.

Whatever vividness would be, it should contribute to the difference between, say, imagining something that is loathsome and imagining something with loathing. Walton's account, in effect, replaces this latter notion with that of the first-person fictional truth that $I$ am in a state of loathing. This gives his account an attractive simplicity of elements for, rather than resting on an additional and undefined concept of the vivid, it simply includes one more fictional truth to be imagined. ${ }^{7}$ However, part of the reason appeal

\footnotetext{
${ }^{6}$ This, of course, is one of the lessons of the later work of Wittgenstein.

${ }^{7} \mathrm{My}$ criticisms here are directed at the claimed role of fictionality and fictional truth in both the framing of and the solution to the problem of art and emotion. Walton himself recognizes activities of imagination that are nonpropositional, but his account of the role of emotion is centered on fictional truths concerning own's psychological state. (See 42-43: "It is by mandating the imagining of propositions that props generate fictional truths. But imagining is not exclusively propositional. Imagining a bear goes
} 
to vividness is made in these discussions is to point to something that is part of the causal difference between cool dispassionate imagining and the imagining that involves getting carried away. One aspect of the phenomenon this is meant to capture is the fact that different kinds of imagining involve different kinds of effort, draw on different kinds of resources within the person, and may thus require such things as being receptive in the right way, or having had certain experiences. On Walton's picture, on the other hand, if vividness has any essential role, it can be only that of making it possible for me to imagine an additional fictional truth with a different content: that I am in a state of loathing. But it is hard to see how vividness could have any such role as a generator of further fictional truths. For it would be something of a mystery why there should be this kind of causal requirement for imagining something with a particular content. There are no special causal requirements for imagining the fictional truth that the moon is made of green cheese, or that someone else is horrified. Nothing simpler. So it's hard to see why there should be any special causal conditions for my imagining the fictional truth that $I$ am in such a state. If you've got the proposition, you should be able to go ahead and imagine it. And if it were said here that "merely" imagining it isn't the phenomenon we originally had in mind, then that suggests that the positing of fictional truths does not answer to the original problem.

Rather, what is vivid about some representations is that they provoke the mind to do various things (relating, contrasting, calling up thoughts); they need not, and normally do not, do so by provoking one to imagine an additional set of fictional truths. What is meant by "liveliness"' in such contexts is a matter of various kinds of both spontaneous and directed mental activity. Both vividness and the emotional engagement with fictions should be seen as, irreducibly, aspects of the manner of one's imagining, and not as part of the content of what is imagined. For the same questions and distinctions can be applied to any fictional truth imagined, whether it concerns the unravelling of Macbeth's assassination plot

beyond imagining that there is one.")

Inasmuch as nonpropositional imaginings are not concerned with the generating of fictional truths, they are not concerned with generating fictional truths about one's emotional state, and hence cannot be part of the argument that what is felt at the theater involves 'quasi-emotions'. 
or one's own psychological response to it. You can imagine the murder of Duncan, and in addition you can imagine that you are horrified. And if you can imagine the former dispassionately, then you should be able to imagine the latter dispassionately as well. Casting the phenomenon in terms of the generation of fictional truths provides no way to describe the difference between the case where I imagine dispassionately that I am horrified (say, as part of a simple hypothetical supposition) and the case where I imagine this as part of getting "swept up" in the fiction. As long as the emotional component is understood as part of the content of what is imagined, we can in principle draw the distinction between imagining this in a cool detached manner and imagining it with emotional involvement (the manner of imagining). And this is to leave the phenomenon to be explained out of the analysis.

Walton is explicit about an assumption that is common in these discussions but rarely given much attention. Early in his book (28) he says that imagination in general is essentially self-referring, meaning that when I imagine some fictional truth, I imagine myself believing it or being aware of it. This is immediately to place an aspect of one's psychological state of imagining as part of the content of what is imagined, whereas without that assumption it would have seemed that many or most exercises of the imagination need not include any part of the person's mental life as part of their content. This is certainly true about simple hypothetical suppositions, and counterfactual beliefs would seem to be no more essentially self-referring than are other beliefs. It should be possible, for example, for me to imagine that I am the victim of a successful deception and betrayal, without imagining that I am the knowing victim of such a betrayal. Hence I imagine something as being true, and myself as not believing it, all in the same imagined world; just as a person can imagine being in a state of anticipation without imagining this with anticipation. Conversely, one can imagine believing something while also understanding it to be false in the world imagined, as when one imaginatively reconstructs one's former state of mind as a believer in the tooth fairy. In all these cases the state of affairs and one's belief about it are recognized as two distinct and independent contents of imagination.

Indeed, it is internal to the nature of specific aesthetically relevant forms of emotional imagination that there is a perceived difference between what is true in the world imagined and the state 
of mind one is imaginatively participating in. We can see this, for instance, in the imagination involved in the experience of tragic irony, which requires both the participation in the unknowing state of mind of the hero as he declares that he is searching for the slayer of Laius, and our appreciation in the audience of the disharmony between his sense of his situation and what his situation really is. Nostalgic or wistful forms of imagination are also structured this way, for it is part of their essence to capture a sharp sense of the difference between the world as represented by the naive state of mind of one's former self and the (then) unappreciated truth about the transience of that familiar world, or the vanity of the hopes that supported one then. In a single act of imagination one imagines a certain state of mind, and a certain state of the world, and a crucial distance or lack of fit between them.

The assumption of the essentially self-referring character of imagination gets some of its initial plausibility from the concentration on examples of visual imagination. For to imagine visually the murder of the sleeping Duncan is indeed to picture the scene from some point of view or other. This is not, however, the same as to say that part of what I imagine is that I witness the murder from this point of view. Presumably, if he had had proper suspicions in time, Duncan himself could have imagined, visually and vividly, that he might be murdered in his sleep. He might, then, visualize this from some point just above his sleeping figure on the bed, perhaps from the point of view of one of the murderers. But this would not mean that it is part of what he (incoherently) imagines that he sees himself asleep from some point above his own body. ${ }^{8}$ On the contrary, a crucial part of the emotional tone of his imagining would be his sense of fear and outrage at the idea of being attacked while completely defenseless and unaware. The distinction between what is within the scope of what is imagined and what is

\footnotetext{
${ }^{8} \mathrm{~A}$ familiar but remarkable fact about the psychology of memory is that the visual phenomenology of a memory of performing an activity like swimming across a lake will often be presented from a point of view above or behind the figure doing the swimming (that is, oneself). This is one of the more graphic examples of the nonidentity of the memory image and the content of what is remembered (for one surely doesn't remember any such experience), and the same thing applies to the relation between the phenomenology of visual imagination and its content.
} 
outside it is crucial here. If we are going to talk about mental images in the first place, then we must recognize that it is a formal property of any such visual representation as an image or a picture that what is shown must be shown from some point of view or other, just as it is a formal property of anything that is thought or conceived of that it is conceived of by someone. But as with Berkeley's tree in the quad, it doesn't follow that it is part of the content of what is imagined or "perceived" that it is something imagined or perceived by anyone. The Berkeleyan claim that nothing can exist unperceived is no more true of the "internal" world of what is imagined than it is of the "external" world. ${ }^{9}$

Here I am trying to prize apart the notion of fictional truth from that of engaging in a particular mode of imagining. With respect to visual imagining, the point is that to imagine something visually is not the same as to imagine seeing it. "Visual" here refers to a particular type or manner of imagining, and it thus refers to a genuine (that is, "real world") psychological fact about the person doing the imagining, and need not be within the scope of what is imagined or construed as fictionally true. It really is true that, say, Duncan visually imagines his murder from a particular point of view. But it is neither true nor imagined ("fictionally true") that he sees himself from this point of view. In general, phenomenological features of imagination are neither necessary nor sufficient for determining the content of what is imagined. Such features are not necessary because one could imagine that the huddled figure under the bed-sheet is oneself, without that being anything that is discernable in the image. That it is oneself lying there is the intentional content given to it, independent of having anything "present to consciousness." And such features of the image are not sufficient for content either, since the fact that the point of view from which this is pictured is that of a viewer watching someone asleep does not entail that the imaginative content is that of watching oneself sleeping.

\footnotetext{
${ }^{9}$ Walton himself notes the Berkeleyan analogy on page 237 , note 24; but he feels such problems need not be addressed within his theory since "they are largely if not entirely irrelevant to appreciation and criticism" (238). Part of what I am trying to show here is that such questions about the nature of imagination, including determining what is and is not part of its content, do have various points of relevance for appreciation and criticism, as well as (perhaps more directly) for philosophical aesthetics.
} 
As suggested earlier, emotional aspects of imagination, such as imagining something with apprehension or regret, should also be seen as part of a manner of imagining and not as something that must belong to the content of what is imagined. Like imagining something visually, imagining something with apprehension is the description of something the person is actually engaged in, and is not something within the scope of what is imagined. To imagine something with feeling is not the same as to imagine having that feeling. These are independently functioning contents as well. For I could imagine being afraid of the dark without now feeling anything. And, on the other hand, I could imagine, with feeling, some situation in which it is central to the content of what I imagine about myself that I do not feel anything (in particular)—for example, I imagine vividly and hopefully a situation in which I am free of some neurotic anxiety, or have no memory of what's worrying me now. The facts about the manner in which this is imagined lie within the actual and not the imagined world. Only the content of what is imagined is fictional in any sense. The way in which it is imagined, on the other hand, is an aspect of the activity of imagining that one is really engaged in, a fact about one's real psychological life and attitudes.

When we think of what the audience feels as falling within the scope of what is fictionally true, this suggests an innocence or lack of real-world accountability in those responses that doesn't fit how we actually think or talk about what we feel in the theater or in other fictionalized contexts. Rather, the responses of laughter, lust, indignation, relief, delight in retribution, etc. are normally treated as expressions of genuine attitudes that we actually have, and are esteemed or repudiated accordingly. It would not be at all accurate to say that just as we do not really believe the various fictional truths that make up the world of the story, so we do not really have the attitudes that are expressed in our responses. For although a person typically won't find it a disturbing discovery about himself that he is capable of imagining this or that fictional truth, he might well be disturbed by what he finds himself feeling at the movies. Such reactions would be hard to understand if what he felt was as remote from his real temperament as the events on the screen are remote from his real beliefs about the world. The person who finds himself chortling with appreciation at a racist joke cannot excuse himself by insisting that he no more really shares in the attitude 
his laughter expresses than he really believes the fictional truths that make up the details of the story. And in this his situation is no different from that of the person who is either moved or repelled by the representations of passion in melodrama, revenge fantasy, or Masterpiece Theater. When Oscar Wilde said that one must have a heart of stone to read the death of little Nell without laughing, his point requires reference to people's real hearts, and to the sentimental corruptions of people's actual attitudes. And the ordinary practice of eliciting, sharing, and criticizing such emotional responses to fictions would be a quite bizarre and pointless exercise if these responses and the attitudes they express were not located on this side of the counterfactual divide. This is not to say that there are not important differences between the pity or grief felt for little Nell and our responses to people we share the real world with. However, as described in sections 1 and 2, the "nonfictional" class includes cases as different from each other as any of them are from the fictional cases, and for this reason I think it is less misleading to see them as different types of, for example, pity, rather than to think of the difference as akin to that between a real horse and an imaginary one.

4.

There are various ways in which what one imagines relates to one's genuine attitudes. The imagination involved in various thought experiments, for example, expresses commitments about logical possibility and about what follows from some initial set of assumptions; and in moral reasoning, the response to imagined cases is part of what reveals the principled nature of a moral judgment (or its failure).$^{10}$ Such differences in the relations between imaginary worlds and real commitments will naturally make for differences in the kinds of difficulty or resistance there may be concerning different imaginative tasks. Aesthetic contexts will also in various ways reveal the complex relations between genuine attitudes and imaginary responses, and in this final section I take up an extended

\footnotetext{
${ }^{10}$ One helpful discussion of these and related aspects of imagination is in Stanley Cavell, The Claim of Reason (Oxford: Oxford University Press, Clarendon Press, 1979), most explicitly on pages $145-59$, but also in chapters 7 and 9.
} 
discussion of one broad type of resistance whose pervasiveness forms part of the general argument against analyzing the role of emotion in terms of fictional truths.

What we do when we imagine the propositions concerning Macbeth's accession to the throne seems to be a very different sort of thing from what we do when we imaginatively enter into such events and respond with either horror or anger, and our stake in our imaginings is different. This can be seen if we compare how we would respond to the prescription to imagine an alternate set of fictional truths here. If the story tells us that Duncan was not in fact murdered on Macbeth's orders, then that is what we accept and imagine as fictionally true. If we start doubting what the story tells us about its characters, we may as well doubt whether it's giving us their right names. However, suppose the facts of the murder remain as they are in fact presented in the play, but it is prescribed in this alternate fiction that this was unfortunate only for having interfered with Macbeth's sleep that night, or that we in the audience are relieved at these events. These seem to be imaginative tasks of an entirely different order, and were we to succeed in performing them at all (that is, in any way comparable to the way we actually respond to the events of the play-that is, not dispassionately), that would involve a greater friction with our genuine emotional attitudes, or friction of a different kind, than does the contrast between what we really believe about witches or ghosts and what the play makes fictionally true about them. It might well be a form of imagination in which we are unwilling to engage. It is not clear how or why this should be so, especially when we consider how rarely literature provides us with anything like a sharp line between what we may think of as the more "straight" factual and the more highly "charged" among the descriptions given in the text. And after all, it might be said, you're not being asked to believe anything different from what you do believe, so why feel compelled to repudiate the very imagining of something as though you were repudiating some false opinion?

To my knowledge, the nature of such imaginative resistance does not receive much explicit discussion in the history of aesthetics, even though so many familiar terms of aesthetic criticism (for example, the sentimental, the pretentious, etc.) can be seen as expressing judgments of this kind-roughly, judgments of the distance between what we are enjoined to feel and what we are 
actually inclined to feel. One brief discussion I know of is contained in the closing paragraphs of Hume's essay Of The Standard of Taste, where the role of one's emotional experience in the theater is discussed in connection with just this sort of clash in imagination, and which throws some light on the complex relationships between one's genuine attitudes and what and how one imagines. ${ }^{11}$ When a story or play represents differences of "innocent peculiarities of manners" between our own world and the world depicted, Hume tells us, we do not allow this disparity of attitudes to break our participation with the fiction.

But where the ideas of morality and decency alter from one age to another and where vicious manners are described without being marked with the proper characters of blame and disapprobation, this must be allowed to disfigure the poem, and to be a real deformity. I cannot, nor is it proper I should, enter into such sentiments, and however I may excuse the poet on account of the manners of his age I never can relish the composition.

Where speculative errors may be found in the polite writings of any age or country, they detract but little from the value of those compositions. There needs but a certain turn of thought or imagination to make us enter into all the opinions which then prevailed and relish the sentiments or conclusions derived from them. But a very violent effort is requisite to change our judgment of manners, and excite sentiments of approbation or blame, love or hatred, different from those to which the mind from long custom has been familiarized. And where a man is confident of the rectitude of that moral standard by which he judges, he is justly jealous of it, and will not pervert the sentiments of his heart for a moment in complaisance to any writer whatsoever.

Here Hume distinguishes between two different possible objects of imagination: speculative errors, on the one hand, and ideas of morality and decency different from ours, on the other. The former require nothing more than the acceptance of something as true-in-the-fiction, and in doing so we commit ourselves in no way at all as to our genuine beliefs about the matter. The latter, by contrast, require a "violent effort" of the imagination the result of which does not leave our genuine attitudes undisclosed or unmo-

\footnotetext{
${ }^{11}$ Walton discusses this passage and some of the problems it raises for determining what is true in the world of the fiction, on pages 154-55.
} 
lested, but rather threatens to "pervert the sentiments" of one's heart. But why should this be? Hume's problem here does not stem from any assumption that we always respond in these asymmetrical ways (for surely we do not), or that we will all draw the lines in the same places (between "speculative" and other errors). Rather, I take his problem to concern the meaning of such imaginative opposition on any of the occasions when it does happen, and this remains a genuine question regardless of the variability of such reactions. Why can we not, as it seems, treat the judgments of morality and decency the same way we treat any other judgments, and accept as fictionally true what the story tells us (or implies) is true, and comfortably leave our genuine attitudes at the door? What happens to our sense of distance at that point, the distance between what we can imagine and what we actually believe? The suggestion here is that we cannot treat these as on a par with other fictional truths. The difficulty, apparently, does not have to do with the imagining of characters with moral beliefs different from our own, but rather with imaginatively entering into a fictional world where moral reality is different from what we take it to be. We can easily "accept" the existence of ghosts as one of the fictional truths implied by the story, but it seems we cannot similarly "accept" it as true in that fictional world that, say, the murder of one's guest (as it is actually depicted) is not to be condemned. Rather than accepting it as true in this fictional world, we will not budge even hypothetically from our real beliefs here, but will instead remove such attitudes from the realm of fictional truth altogether and instead ascribe them to the author and/or audience of the story.

Are such reactions simply Philistine or narrow-minded? Surely they sometimes are, and often enough a person is justly charged with failing to bracket his own culture-bound judgments enough to respond to what is there in the work. But the problem Hume's text points us to could be dismissed only if one thought that such resistance was always and only the expression of such narrow-mindedness; and any temptation in that direction should be checked by appreciation of how general the phenomenon is. Far from being restricted to moral contexts, it is part of any aesthetic response that claims a distinction in principle between the emotional solicitation of the work (whether as laughter, or pity, or horror) and the response one actually gives to it. No work or performance is either funny or pitiable or horrifying just on its own say-so, notwithstand- 
ing the need for allowing one's sense of the pitiable, etc. to be educated by the work. Here as elsewhere, there is the problem of negotiating the demands of receptivity, on the one hand, and the engagement involved in taking the claim of the work seriously, on the other. If it is Philistinism always to impose one's current attitudes on a work or else simply fail to respond to it, there is nonetheless no solution to be found in attempting to abstract away from everything in oneself that the work is trying to reach and provoke. Hume's own case has the advantage of relative clarity for examination, but the problem itself is wider than legitimate worries about moralism.

In the passage quoted, Hume makes a few somewhat halfhearted attempts at explanation, but his answers are brief and do not appear to strike Hume himself as terribly persuasive. So, for instance, he suggests that such conflict stems from the fact that the reader is just so unshakably "confident of the rectitude of that moral standard by which he judges." But this will not do since, however dogmatic we may in fact be in these matters, surely many of us are even more confident of the rectitude of our judgments concerning the existence of vampires or leprechauns, and yet we can manage with stories about them well enough. So confidence in the correctness of our ideas cannot explain imaginative resistance. Similar remarks would apply to the familiar Humean appeal to the inertia of those habits of thought and sentiment, "to which the mind from long custom has been familiarized." For again, that fails to distinguish anything about this particular class of our long-accustomed attitudes. We are equally long-accustomed to the habits of thought and belief that we positively delight in subverting through fictions. Nor can it be that we find the contrary of the moral truth as we see it to be just too unpleasant to imagine, when we consider some of the truly revolting and horrifying things we do take pleasure in imagining in our best fictions.

It is particularly striking in Hume's text how close by one another are the claim of the unalterable character of our moral convictions, on the one hand, and the claim of their extreme vulnerability and fragility, on the other. We are told that it is only with great difficulty that we can entertain sentiments of praise or blame different from those to which we are accustomed, and that "where a man is confident of the rectitude of that moral standard by which he judges, he is justly jealous of it, and will not pervert the senti- 
ments of his heart for a moment in complaisance to any writer whatsoever." This raises the question of why, if this man is so confident and secure in his opinions, he is yet so hypersensitive about imagining the truth of different opinions, so that he fears he cannot imagine in this way without the threat of perverting that very judgment of his of which he is so confident. What kind of confidence is this, that dares not even submit itself to imagining the contrary of its judgment? And again, an appeal to the confidence of one's convictions cannot explain why this opposition does not extend over the whole range of one's judgments, including those held with an even greater confidence than are many of one's moral convictions.

Whatever the ultimate explanation of such conflict, it seems to argue against thinking of the fictional world of the work as a separate domain, existing purely by stipulation. For although we may take it as simply given by the story that such and such events took place, this is not so with respect to the idea that they are cruel or ludicrous. Perhaps even the author of The Golden Bowl believed that the relationship between Adam and Maggie Verver represents a kind of exemplary rapport between father and daughter (rather than something morbid, manipulative, and vaguely incestuous), but he does not make this true in anything like the way he makes it true that they greet each other with the words he gives them to say. Or further, we may at times feel that an author is somehow unfair to one of his characters, as some have felt about James's own treatment of Charlotte Stant, ${ }^{12}$ a response that would be difficult to understand on the assumption that the characters have only that reality that the author has given them. We seem, then, to accept a role for the reader's (or audience member's) own sense of what is blameworthy or admirable in determining what is true in the fiction. And it is the implicit repudiation of this role in works we find, say, sentimental or moralistic that inspires resistance. In

\footnotetext{
12“'I don't think that her creator does her justice or, perhaps, he does her too much conventional justice, a black, cloth on his head as he sentences her to a living death. But then James appears to accept entirely the code of the class into which he has placed both himself in life and the characters in his book. This means that the woman must always be made to suffer for sexual transgression while the man suffers not at all or, in the case of the Prince, very little" (Gore Vidal, in his preface to The Golden Bowl (New York: Penguin, 1984)).
} 
such cases it can feel as if we are being told not only what to imagine as constitutive of the elements of the fictional world, but also what to conclude from them as well, that is, what genuine attitude to adopt.

This way of putting things may suggest an explanation for what I'm calling imaginative resistance, in terms of relations of necessity between two different sets of facts. It's not hard to see how such an explanation would suggest itself. The reader (or viewer) reserves the right to make up her own mind concerning what's praiseworthy or silly in the fiction because she would adopt such an attitude toward such characters and events in the real world, and she implicitly claims that what applies to the real world applies to any possible world, including the world of the fiction. So the reader feels free to take what she finds to be true in the actual world and import it into the world of this fiction, not of her creation, as one of its constituting truths.

As explanations go, this is clear enough, if brief. The invocation of the concept of necessity obviously raises more issues than can be dealt with here, but I do want to note a few difficulties for seeing it as the answer to our questions about imagination and affective response. If necessity is part of the explanation here, it would have to be under an aspect of that concept different from any I am familiar with. For consider, nowadays philosophers commonly distinguish between conceptual and metaphysical necessity-roughly, between necessity based on relations of meaning and linguistic rules, and a world-grounded necessity that is expressed in the rigidity of names and is said to be empirically discoverable. ${ }^{13}$ Now it seems clear that it cannot be this latter type of necessity that will answer the question raised by Hume. For one of the major motivations for developing the concepts of rigidity and metaphysical necessity in the first place was to divorce questions of necessity from questions of imaginability with which they had been tied for centuries. Nothing can seem easier than to imagine that one had different parents, for example, or that water is composed of something other than $\mathrm{H}_{2} \mathrm{O}$. But advocates of metaphysical necessity insist that this is irrelevant to the question of what necessities really

\footnotetext{
${ }^{13}$ There are, obviously, other varieties of necessity than these, such as nomic necessity, that I am assuming will not be candidates for the relation we are looking for.
} 
obtain. So it doesn't look like the concept of metaphysical necessity can help us with our problem concerning imagination. ${ }^{14}$

At this point, an appeal to conceptual necessity might look more promising, and perhaps more in spirit with Hume's original concerns. We could invoke conceptual necessity with respect to something like supervenience relations between two sets of properties. For Hume himself, in his argument that morality must be based on sentiment and not reason, says that after all the nonmoral facts are in, there is nothing more for the understanding to do. "In the disquisitions of the understanding, from known circumstances and relations, we infer some new and unknown. In moral decisions, all the circumstances and relations must be previously known.... Nothing remains but to feel." 15 So when we accept the various nonmoral facts as fictionally true, that just gives us, by itself, what is morally true in this fictional world. There's simply nothing left to imagine. ${ }^{16}$ We could no more hold the first set of fictional truths constant and imagine the second set as different than we could imagine a world in which the words 'seven' and 'heaven' sound just as they really do in English, but do not rhyme.

There may be something to this, but there are several reasons for thinking this cannot be the right or complete account of our problem. For one thing, even in undisputed cases of supervenience, people do not always add up the "base level" facts the same way, and so can agree about the one set of facts and disagree about the second. And for moral argument that is more than simple harangue to be possible, it must be possible for one at least to entertain the idea that the opposing view is perhaps right, and hence that the nonmoral facts determine a different moral truth from what one thought. If that is so, then such differences must not require that at least one person be in violation of conceptual necessity, as if we could ascribe no coherent judgment to him at all.

\footnotetext{
${ }^{14}$ I don't mean to suggest that matters of analytic or conceptual necessity have such a clear relation to imaginability either. Many people have found the contrary of various logical truths believable, so it would seem they must be in some sense imaginable. At this point my claim is that we cannot rely on a concept of necessity that was designed to be irrelevant to imaginability.

${ }^{15}$ An Enquiry Concerning the Principles of Morals (Indianapolis: Hackett Publishing Company, 1983), 85.

${ }^{16}$ One could, of course, imagine feeling something different, but that would be analogous only to imagining moral sentiments or judgments, not to imagining an alternative moral reality.
} 
For surely not every moral disagreement ends in traded charges that one or the other person is simply incompetent with moral concepts. Rather, we credit the other person with a different moral judgment about the matter, and not as someone simply incomprehensible. In addition, this presumption of comprehensibility might seem particularly pressing in the case of understanding oneself before and after a change of mind about some matter. Granted, some such changes may present themselves to us like conversion experiences, after which we can no longer recognize, or make sense of, a previous self. But a good many others centrally involve such activities as deliberation, imaginative rehearsal, and the offering of reasons. This does not sit well with the idea that some stage of such a change of view must involve violation of some analytic necessity. And finally, I know of no understanding of analytic or conceptual necessity that can accommodate the fact that the judgments we make of such qualities as the cruel or the ludicrous are so contextdependent, relying on a quasi-perceptual appreciation of the situation, and that disagreement here so often is grounded in differing senses of the relevance or relative importance of various factors. Disagreements with respect to such "physiognomic" aspects of judgment are unlikely to be explained by one person's failure to observe some set of analytic truths governing the use of the concept. $^{17}$

If it is true that in ordinary moral disagreement we can and do comprehend the intelligibility of moral views contrary to our own,

\footnotetext{
${ }^{17}$ In "Supervenience Revisited" (in Essays on Moral Realism, ed. Geoffrey Sayre-McCord (Ithaca: Cornell University Press, 1988), 59-75), Simon Blackburn discusses the tension created by two apparent commitments of ordinary moral discourse: first, the supervenience of the moral on the natural and, second, the denial that the supervenience of any particular moral property on a set of natural ones holds as a matter of conceptual necessity. This latter denial of reductionism seems required if we admit that two people can agree on the natural facts of some case, but disagree in their moral judgments, without the conceptual competence of either one of them being thereby called into question.

Blackburn takes these and other considerations to create problems for any realist construal of moral discourse, and to lend support to his projectivist alternative. While I am much less sure of his diagnosis of the difficulties in understanding the modal commitments of ordinary moral discourse, I believe there are difficulties in reconciling the a priori nature of much moral reasoning with a realist understanding of ordinary moral disagreement, although this is not the place to discuss them.
} 
isn't this just the possibility that Hume denies? I think not, but seeing this requires a wider view of the varieties of imagination. In the first paragraph quoted above, Hume speaks of difficulty concerning "entering into sentiments" of morality and decency different from one's own, and the second paragraph contrasts this with the ease with which we "enter into all the opinions which then prevailed," even when they are matters of error. But what "entering into" comes to in each context is a very different matter, and this suggests that the disanalogy he points to may be a dissimilarity concerning not what we imagine so much as how we imagine. Let me explain. When Hume first says, "I cannot, nor is it proper I should, enter into such sentiments," his wording may at first suggest a concern with something like the dramatic rehearsal of the emotions and attitudes represented. But dramatic rehearsal or empathetic identification do not seem to have any role to play when it is a matter of ordinary hypothetical reasoning concerning matters of belief. ${ }^{18}$ Instead, they are feats of imagination that, in a given case, we may or may not find it easy to perform, for they require something more, or other, than the ability to entertain a proposition.

However, Hume's original contrast of the ease with which we imaginatively handle speculative errors and the difficulty we sometimes encounter with respect to other ideas, presumes that it is the same type of imaginative activity in the two cases, just with different contents. It takes but a certain turn of thought for us to be able to hypothetically assume the truth of various speculative propositions that we know to be errors. Presumably the ease with which this is done is in good part a function of the fact that entertaining the hypothesis is quite compatible with a lively sense of the falsity of what we are assuming. But it is just here that the parallel breaks down. For when it comes to drawing the contrast with "entering into sentiments" we do not share, Hume does not in fact discuss the hypothetical assumption of moral judgments we take to be in error, but instead contrasts hypothetically entering into different

\footnotetext{
${ }^{18}$ See Ronald de Sousa, The Rationality of Emotion (Cambridge: MIT Press, 1987): "The function of role-playing is to induce emotions that the unaided imagination cannot summon; it may be necessary for understanding the emotional and practical consequences of those emotions. But the essential contrast with belief is right here: to believe 'if $P$ then $Q$ ', we don't have to role-play believing that P"' (157).
} 
opinions with actually altering one's "judgment of manners" and ideas of decency. For immediately after describing the ease with which we may "enter into all the opinions which then prevailed," he says that a "very violent effort is requisite to change our judgment of manners, and excite sentiments of approbation or blame", different from our own (emphasis added). So it now appears as if we should read the phrase 'entering into different opinions' as referring to actual changes of judgment, whether it is a matter of speculative opinions or judgments of manners. This way we would preserve the parallelism that is required for Hume's comparison to be marking a significant contrast. For it is hardly surprising to be told that it is a simpler thing merely to entertain some proposition hypothetically than it is to change one's actual judgment about anything, whether it be ideas of morality and decency or speculative opinions.

But now, if we must interpret the phrase 'entering into different opinions' as referring to a genuine alteration in one's judgments, there are difficulties in making out the plausibility of Hume's claims. For actually adopting "all the opinions which then prevailed" in a very different age would require quite a bit more than "a certain turn of thought or imagination." (Even a voluntarist about belief doesn't think it's that easy.) Rather, I think we have to distinguish hypothetical and dramatic imagination and the types of resistance appropriate to them. It seems, then, that understanding these passages in Hume requires us to distinguish between two quite different activities, which we may call hypothetical and dramatic imagining. Strictly speaking, neither one of them necessarily involves a genuine alteration of judgment, but in the case of dramatic imaginative rehearsal it's easy to lose track of the difference between supposition and conclusion, between fantasy and acting out. What may sometimes require a "violent effort" in theater or literature is not simply imagining the truth of a proposition (for that typically requires little or no effort at all), nor is it the quite different activity of changing one's real judgments. Hume's language shifts between the one and the other, I think, because of the tendency, not Hume's alone, to restrict imagination to objects of possible belief. If what is resisted in Hume's examples were indeed something propositional, then it would seem that what is resisted could only be either full belief in its truth ("changing one's judgments") or entertaining the assumption of its truth (hypo- 
thetical imagining). But, in these and other cases, what such resistance applies to are the expressions of attitudes that are only partly propositional. We may resist making a certain comparison, or the appropriateness of some metaphor, even when we are not rejecting something we have been given to believe. In such a case one is rejecting a point of view, refusing to enter into it. ${ }^{19}$

Imaginatively adopting a perspective on something involves something different from the sort of imagination involved in ordinary counterfactual reasoning. Hypothetical reasoning involves seeing what would follow from the truth of some proposition. It does not involve either feigning belief in that proposition or determining what would follow from the fact of one's believing it. There need be no reference to oneself, either as believer or as any sort of psychological subject, and one does not determine the truth of a counterfactual by imagining "what it would be like" to believe the antecedent. By contrast, imagination with respect to emotional attitudes may require such things as dramatic rehearsal, the right mood, the right experiences, a sympathetic nature. It thus says more about a person that he is either able or unable to imagine something in this way, and he bears a different responsibility for it. More is revealed and given of oneself than in the case of ordinary counterfactual reasoning, where one only needs to be provided with the proposition in order to reason from the assumption of its truth. By contrast, imagination with respect to the cruel, the embarrassing, or the arousing involves something more like a point of view, a total perspective on the situation, rather than just the truth of a specifiable proposition. And imagining along these lines involves something more like genuine rehearsal, "trying on" the point of view, trying to determine what it is like to inhabit it. It is something I may not be able to do if my heart is not in it. (Compare this with ordinary counterfactual reasoning, which is considerably less topic-specific or dependent on moods.) If we understood better why imagining in such cases requires your heart to be in it, we would understand better what is being resisted when we resist.

\footnotetext{
${ }^{19}$ The difference between what one can assert as a claim, on the one hand, and what one can get one's audience to imagine or associate, on the other, is crucial to the aim and power of effective metaphor. I discuss this in "Seeing and Believing: Metaphor, Image and Force," Critical Inquiry 16 (1989): 87-112.
} 
Although I can't claim to have provided such an understanding here, I hope to have shown that Hume's problem is a genuine one for aesthetics, whatever difficulties remain for his or other philosophical diagnoses of it. The general phenomenon of resistance itself involves both hypothetical and dramatic imagination, and further sorting out of cases will also require attention to the sense of imaginativeness described in sections 2 and 3 . Whatever the fuller account, the complexity and generality of the phenomenon itself, together with the more direct arguments of the earlier sections of this paper, suggest some of the limitations on the usefulness of analyzing imagination in terms of fictional worlds, defined by sets of propositions. It's no secret that the concept of imagination is a heterogeneous and ill-understood one in philosophy. And we understand very little of how exercises of the imagination relate to learning anything about the world, or about our concepts, or about ourselves. Yet we rely on something we call imagination all the time, in and out of philosophy, to inform us about quite weighty matters: the nature of necessity and possibility, the specification of our heart's desire, moral right and wrong. For better or for worse, we seem committed to the idea that imagination is a vehicle of knowledge of various kinds. If this is so, then in such exercises we are not taking our engagement with the world imagined (the fictional world) to be sealed off from what matters to us in the real world. The realm of our emotional responses provides one of the clearer cases in which imagination is not so much a peering into some other world, as a way of relating to this one. ${ }^{20}$

\section{Princeton University}

\footnotetext{
${ }^{20}$ For comments on earlier drafts of this paper I am grateful to Annette Baier, Berys Gaut, Mary Mothersill, Susan Sugarman, Jonathan Vogel, and, especially, Kendall Walton. The paper has also benefited from the comments of two referees for the Philosophical Review, and of audiences at Dartmouth College, the University of Pittsburgh, and the meeting of the American Society for Aesthetics in Philadelphia, 1992.
} 